\title{
Dilatações do tempo em peças do teatro brasileiro moderno: Vestido de Noiva, A Moratória e Auto da Compadecida
}

\author{
Time dilatations in plays of modern brazilian theater: \\ Wedding Dress (Vestido de Noiva), The Moratorium \\ (A Moratória), And Morality play of Compassionate \\ (Auto da Compadecida)
}

Alice Carvalho Diniz Leite ${ }^{1}$

Resumo: Este artigo investiga dilatações do tempo frequentes em três obras modernas do teatro brasileiro: Vestido de Noiva, de Nelson Rodrigues; A Moratória, de Jorge Andrade; Auto da Compadecida, de Ariano Suassuna. Compreendemse como expansão temporal os processos de abarcar, em textos dramáticos, não apenas o presente da ação, mas também acontecimentos pretéritos e/ou situações ocorridas em mundos oníricos.

Palavras-chave: Teatro Moderno. Dramaturgia Brasileira. Tempo.

Abstract: This article investigates time dilatations frequent in three modern literary works of Brazilian theater: Wedding Dress (Vestido de Noiva), by Nelson Rodrigues; The Moratorium (A Moratória), by Jorge Andrade; Morality Play of the Compassionate (Auto da Compadecida), by Ariano Suassuna. The processes of encompassing, in dramatic texts, not only the present of action, but also past events, and/or situations occurred in oneiric worlds, are comprehended as time expansion.

Keywords: Modern Theater. Brazilian Dramaturgy. Time.

1 Doutoranda em Estudos Literários pela Universidade Federal de Minas Gerais. 
O teatro brasileiro moderno, em larga medida, inaugura uma fase vigorosa da literatura dramática nacional: são diversos os autores em exercício, bem como são variadas as temáticas por eles desenvolvidas. A "Pluralidade de tendências", analisada pelo crítico Sábato Magaldi, em Panorama do teatro brasileiro, tem como implicações as dificuldades de rotulação didática dos textos e a expressiva abertura para possibilidades (MAGALDI, 2004, p. 255). Encontrar as características fundamentais desse período dramatúrgico parece ser tarefa árdua e nem sempre executável, principalmente porque, como observa Alberto Guzik, no texto “A Dramaturgia Moderna", presente na obra História do teatro brasileiro, os escritores não se unificam em movimentos coesos, não são alicerçados por ideais artísticos em comum e não trabalham baseados em propósitos análogos (GUZIK, 2013, p. 118). Embora as produções estejam um tanto isoladas, as qualidades estéticas das obras permitem cotejamentos, e algumas se destacam com maior vitalidade. Nesse sentido, há ajustado consenso ao elencar Nelson Rodrigues, Jorge Andrade e Ariano Suassuna como uns dos representativos da época, e, respectivamente, Vestido de Noiva, A Moratória e Auto da Compadecida como dos mais relevantes trabalhos de cada dramaturgo ${ }^{2}$. Essas tramas apresentam, mesmo nas distâncias, certas similaridades. Entre elas, ressalta-se a preferência por temporalidades dilatadas que não necessariamente seguem parâmetros lineares, sucessivos e ininterruptos. A começar por Vestido de Noiva que, em 1943, se divide em três planos: alucinação, memória e realidade. Seguidamente, A Moratória que, representada em 1955, despedaça acontecimentos entre os anos emblemáticos de 1929 e 1932. Por último, Auto da Compadecida que, em 1956, se ramifica entre fatos da vida e da morte das personagens.

2 Críticos do teatro nacional, ao selecionarem os representantes da dramaturgia moderna brasileira, percorrem interessante linha de afunilamento: Décio de Almeida Prado, em O Teatro Brasileiro Moderno, escolhe sete autores - Nelson Rodrigues, Jorge Andrade, Ariano Suassuna, Gianfrancesco Guarnieri, Oduvaldo Vianna Filho, Dias Gomes e Augusto Boal. Na lista de Sábato Magaldi, em Panorama do teatro brasileiro, repetem-se os quatro primeiros; e, na de Alberto Guzik, em "A Dramaturgia Moderna”, apenas os três primeiros. 
Das considerações sobre a forma dramática, primeiramente, realçam-se argumentações encontradas na Poética de Aristóteles, escrita no período clássico grego (séculos V-IV a.C.). O filósofo estagirita compõe uma série de descrições e normas, sobretudo, acerca da tragédia mas também da comédia e da epopeia ${ }^{3}$. Distâncias entre essas tipologias variam, por exemplo, de acordo com as imitações priorizadas e com a extensão das obras. Nesses termos, tragédias e epopeias procurariam representar seres superiores, enquanto as comédias, seres inferiores e ridículos (1448a 9-16) ${ }^{4}$. As epopeias não incluiriam limitações de tempo, e as encenações de tragédias buscariam abarcar uma única passagem de sol, ou pouco ultrapassá-la $\left(1449 \mathrm{~b}{ }^{9}\right)$. As ações das tragédias seriam completas, encadeadas por princípio, meio e fim (1450b 24-26), bem como teriam duração assimilável pela memória (1451a). Em suma, ainda de acordo com Aristóteles, tragédias mostrariam indivíduos de reputação e fortuna que, pela ocorrência de um erro, caminhariam da felicidade para a infelicidade $\left(1453 \mathrm{a}^{7}\right)$. Nas recomendações aristotélicas, percebem-se as fronteiras delimitadas entre a forma do gênero dramático e a do gênero épico: se a representação da primeira seria enquadrada em vinte e quatro horas, a segunda não apresentaria restrições de cronologia. Interpretadas e reinterpretadas, essas questões adquirem status de princípios a serem seguidos desde a própria Antiguidade grega e romana. E esse caráter receituário, como lembra o teórico Jean-Jacques Roubine, na obra Introdução às grandes teorias do teatro, é intensificado do século XV até os finais do XVIII, na Europa, principalmente devido às republicações e traduções comentadas da Poética (ROUBINE, 2003, p. 24-26)5.

$\mathrm{O}$ enrijecimento da forma dramática, envolvida por moldes

3 Contrastes entre descrição e norma, na Poética de Aristóteles, são analisados, por exemplo, por Roberto Acízelo de Souza, na obra Teoria da Literatura. Conforme os estudos do autor brasileiro, predominam nos enunciados do filósofo grego especulações mais abertas e expositivas (SOUZA, 1995, p. 13).

4 Todas as referências à Poética de Aristóteles seguem as traduções de Eudoro de Sousa.

5 Todas as citações à obra Introdução às grandes teorias do teatro, de Jean-Jacques Roubine, seguem a tradução de André Telles. 
predeterminados, exclui a manifestação de traços épicos - entre eles, a possibilidade de conter episódios da vida até a morte de uma personagem, ou a de ordenar cenas por meio de frases, como "dois anos antes", ou "seis anos depois". Rejeições como essas persistem ainda nos primórdios da modernidade, iniciada na época renascentista. As configurações do drama absoluto, nas terminologias de Peter Szondi, em Teoria do drama moderno, estabelecem arranjos fechados em si mesmos. Nessa perspectiva, valorizam-se as relações intersubjetivas marcadas nos diálogos entres duas ou mais personagens, assim como os acontecimentos desenrolados no presente da ação ${ }^{6}$. A unidade de tempo, especialmente, passa a ser compreendida como a sucessão ininterrupta de presentes absolutos, a qual recusa, por consequência, a descontinuidade espacial. Importa mencionar que as peças religiosas da Idade Média e as peças históricas de Shakespeare são, previamente, eliminadas do corpus teórico szondiano em razão da presença nelas de um eu-épico. Acelerando alguns anos, em meados de 1880, sobrevém na Europa a crise do drama, baseada nos contrastes das produções elaboradas com as supostas leis aristotélicas. Processos de ruptura trazem à enunciação momentos pretéritos vivenciados pelas personagens, e esses instantes passados não são meros detalhes dos intercâmbios comunicativos. Pelo contrário, são o principal fio condutor das obras de Ibsen, de Tchékhov, de Strindberg, de Maeterlinck, problematizadas longamente por Szondi. Ademais, há nessas dramaturgias irrupções da esfera íntima das personagens, evidenciada por reflexões monológicas ou intrassubjetivas.

A abertura da forma dramática estende-se em movimentos graduais de flexibilização: primeiro, as unidades aristotélicas de tempo e de espaço são intuídas como ações sobrevindas, necessariamente, no presente intersubjetivo. Com as alterações de paradigma, as dramaturgias englobam também o passado e a dimensão intrassubjetiva das personagens.

6 Todas as alusões à Teoria do drama moderno, de Peter Szondi, seguem a tradução de Luiz Sérgio Rêpa. 
Tais mudanças não cessam de transbordar as antigas limitações do gênero dramático e, assim, surgem obras que não obedecem à estrutura linear de início, meio e fim. Acontecimentos fabulares despedaçamse em ordenamentos não mais conhecidos em toda sua amplitude, como esclarece Jean-Pierre Sarrazac, em Poética do drama moderno7. Fragmentos justapostos e lacunares pretendem, inclusive, abarcar a trajetória completa vivenciada pelos protagonistas. Essa nova lógica de composição, rompendo definitivamente a unidade temporal, incorpora dispositivos do gênero épico, como a viabilidade de retornar ao passado. Os cinco operadores desdramatizantes, como são nomeados pelo teórico francês, são marcadamente regressivos: (i) a retrospecção inverte a direção da trama, em ritmo testamentário, e permite a eclosão de lembranças; (ii) a antecipação divulga, previamente, fatos da composição e, depois, regressa a eles; (iii) a optação multiplica as versões possíveis, e até inconciliáveis entre si, de um mesmo drama; (iv) a repetição-variação conduz à reincidência de episódios semelhantes; (v) a interrupção viabiliza, entre os eventos, paradas facultativas e digressões. Vale frisar que nenhum desses procedimentos contrafabulares significaria o fim do drama. $\mathrm{Na}$ verdade, demonstrariam a capacidade de a forma dramática reinventar-se permanentemente.

Esses novos contornos do drama europeu, assentados a partir do final do século XIX, pertencem ao que Sarrazac (2017) batiza como drama-da-vida. Em síntese, as modificações concernem às transgressões de ordem, extensão e completude, bem como à valorização do âmbito intrassubjetivo. Nessas escolhas, sobressai-se certo enfraquecimento das concepções interpretadas em Aristóteles, as quais se limitam a exibir somente um dos aspectos na trajetória de um herói - a inversão da felicidade para a infelicidade, no caso das tragédias. Por conseguinte, extenuam-se

\footnotetext{
7 Todas as referências à Poética do drama moderno, de Jean-Pierre Sarrazac, seguem as traduções de Newton Cunha, J. Guinsburg e Sônia Azevedo.
} 
ainda as configurações do drama absoluto, ou seja, as ações intersubjetivas reservadas ao momento presente. O drama-da-vida, em vias gerais, caracteriza-se pela mudança de medida: além das transformações no ritmo interno das obras teatrais, com o acréscimo dos dispositivos mencionados, há o alargamento temporal das dramaturgias. Assim, torna-se possível apreender, em uma única composição, a vida inteira de uma personagem, do nascimento até a morte. As operações modernas, conforme Sarrazac (2017), desembocam em, pelo menos, seis modelos de drama-da-vida: (i) o romance dramático incorpora propriedades caras ao gênero épico, seja na adaptação de narrativas para o palco, seja nas longas descrições, em rubricas, sobre as personagens ou sobre o cenário; (ii) a cena sem fim, fragmento que se desenvolve continuamente, possui o final em aberto e a viabilidade latente de um recomeço; (iii) o drama em estações desenhase em moldes fixos, lembrando o teatro medieval religioso e a trajetória exemplar de martírios da existência; (iv) a crônica épica interliga os episódios dramáticos de maneira descontínua e contingente, podendo atravessar uma vida inteira; (v) o fim (fins) de jogo concentra-se na última fase experimentada por uma personagem que, na agonia da morte, inicia o julgamento final sobre a própria biografia; (vi) o jogo do sonho dissipa as relações de causa e efeito, as quais são substituídas pelas montagens aleatórias e oníricas, de espaços e tempos diversos.

O conjunto de recursos do drama-da-vida exalta, sistematicamente, a irregularidade cronológica e incentiva hibridizações entre o tempo do gênero dramático e o do gênero épico. Distender as fábulas para os acontecimentos de uma vida completa assinala-se como uma das características principais do teatro moderno europeu, de acordo com JeanPierre Sarrazac (2017). As argumentações desse teórico francês, assim como as de Aristóteles (2008) e as de Peter Szondi (2001), não versam sobre o teatro brasileiro. Entretanto, há diálogos possíveis entre as teorias estrangeiras mencionadas e os dramas Vestido de Noiva, do pernambucano 
Nelson Rodrigues, A Moratória, do paulista Jorge Andrade, e Auto da Compadecida, do paraibano Ariano Suassuna - assim como outras composições desses e de outros autores nacionais. Nesse sentido, em alguma medida, segue-se a direção de Elen de Medeiros que, em Um teatro bagunça, indica, sobretudo, as propostas szondianas e sarrazaquianas como metodologia para estudar a dramaturgia brasileira, tanto a moderna, quanto a contemporânea (MEDEIROS, 2017, p. 132).

A fábula de Vestido de Noiva inicia-se com os estrondos de um desastre: "buzina de automóvel. Rumor de derrapagem violenta. Som de vidraças partidas. Silêncio. Assistência. Silêncio" (RODRIGUES, 2004, p. 9). Esse quadro introdutório remete-se ao atropelamento de Alaíde que, em seguida ao acidente, na mesa de cirurgia de um hospital, começa a devanear por suas memórias e por suas invenções alucinatórias. Nos instantes fronteiriços entre a vida e a morte, a protagonista oferece aos leitores e espectadores acesso às suas íntimas lembranças e aos seus desejos não plenamente realizados. O breve resumo anuncia a revisita ao passado e a fatos precedentes ao drama e, assim, vislumbra o operador desdramatizante da retrospecção. Concentrar na última fase de uma existência oportuniza ainda a construção de um fim de jogo, método propiciador do julgamento final de uma personagem sobre si mesma. A criação, dividida em três planos, confunde momentos da realidade, de um lado, com instantes da imaginação criativa da figura principal, de outro. Os primeiros mostram a jovem desacordada, em companhia de indivíduos sem nome nem profundidade psicológica, vestidos como médicos, intervindo com bisturis e tesouras no corpo da moça agonizante. Exibem também jornalistas caçando novidades sobre o ocorrido, aguardando o furo de reportagem, a extenuação da mulher rica. Nessas cenas, os diálogos revelam-se sempre intersubjetivos no presente da ação - de modo semelhante ao drama absoluto, descrito por Szondi (2001). A concatenação entre elas fragmenta-se no decorrer dos eventos, apesar de serem organizados em trajetórias cronológicas. 
Os demais episódios focalizam conversas entre Alaíde e Madame Clessi, uma dona de bordel que, segundo a ficcionalização teatral, morrera assassinada nos anos 1905 - cerca de duas décadas anteriores ao nascimento da protagonista. Ambas as personagens nunca se viram pessoalmente, a jovem delirante conhece apenas o diário pessoal deixado pela cortesã. Nessas circunstâncias, enquanto a figura principal narra reminiscências pretéritas, os intercâmbios comunicativos aparentam ser intersubjetivos. Todavia, a meretriz existe apenas como fruto de uma fantasia descontrolada, como uma espécie de duplicação da própria moça desvanecida. De algum modo, é como se Alaíde falasse sozinha, consigo mesma, intrassubjetivamente. $\mathrm{O}$ encadeamento temporal entre alucinação e memória percorre linhas levemente consecutivas e progressivas, seguindo perguntas e curiosidades de Madame Clessi: "mas seu marido, seu pai, sua mãe... e Lúcia?” (RODRIGUES, 2004, p. 19), ou: "o que foi que as duas disseram naquela hora?” (RODRIGUES, 2004, p. 48). Não obstante, a sucessão de camadas apresenta-se irregularmente, pois nem mesmo a protagonista sabe a temporalidade exata dos fatos: "tudo está tão embaralhado na minha memória! Misturo coisa que aconteceu e coisa que não aconteceu. Passado com o presente" (RODRIGUES, 2004, p. 51). Além disso, transições desses eventos para o nível da realidade desfiam-se por meio do dispositivo da interrupção, por fissuras que despedaçam as ações em fragmentos parcialmente autônomos. Som de trevas, mudanças no posicionamento das luzes, cortes abruptos de música, enunciados de médicos e jornalistas sinalizam as passagens repentinas dos planos imaginativos ao da, por assim dizer, verdade ficcional.

As cisões de Vestido de Noiva em três diferentes planos instauram a manipulação dos tempos e, sobretudo, as incertezas relativas à autenticidade das ocorrências inventariadas. A própria Alaíde incentiva dúvidas, embaraçando presente e passado, como dito anteriormente, titubeando ao sentenciar: "me esqueci de tudo. Não tenho memória - sou 
uma mulher sem memória" (RODRIGUES, 2004, p. 12), e buscando insistentemente: "mas todo mundo tem um passado; eu também devo ter" (RODRIGUES, 2004, p. 12). Em tais situações, a personagem estrutura o mecanismo da optação, uma vez que há a multiplicidade de interpretações admissíveis. Alguns questionamentos ficam até sem resposta: a jovem matou ou não o marido? Ela roubou ou não o namorado de Lúcia? Os episódios são montados como um exemplo de jogo dos sonhos, com acontecimentos organizados aleatória e ambiguamente, seguindo os fluxos de uma mente onírica. Por esses ângulos, o ritmo do drama rodrigueano permite saltos imprevisíveis de uma lembrança à outra, inclusive, podendo se delongar por uma vida inteira - embora a protagonista acumule esforços para se lembrar do casamento com Pedro e da experiência matrimonial. Não por acaso, segundo o crítico Sábato Magaldi, em Panorama do teatro brasileiro, essa obra teatral "veio rasgar a superfície da consciência para apreender os processos do subconsciente, incorporando por fim à dramaturgia nacional os modernos padrões de ficção" (MAGALDI, 2004, p. 218). A composição moderna de Nelson Rodrigues expõe as três camadas de Alaíde que se convergem em um único texto, bem como que se dissolvem em três contextos finais. Extenuam-se a realidade, a alucinação e a memória.

Subverter a disposição rigorosa do tempo parece ser também a questão fundamental de A Moratória. Esse enredo de Jorge Andrade divide o cenário em dois espaços diferentes e, parcialmente, complementares: à esquerda, as ações desdobram-se em uma enorme fazenda cafeeira, no ano de 1929; à direita, em uma pequena cidade, por volta de 1932. As personagens de ambos os seguimentos são as mesmas - Joaquim, Helena, Lucília e Marcelo, todas elas pertencentes a uma família tradicional e aristocrata de São Paulo. Como se pode observar, a disparidade entre as cenas é resultado de uma decadência financeira. A data de 1929 remete-se à crise generalizada nos preços do café e, por consequência, 
ao empobrecimento paulatino de grandes estancieiros. Justapondo os quadros, almeja-se enfatizar o declínio irreversível de uma classe que, acostumada com a vida farta na zona rural, precisa sobreviver na escassez da urbanidade. Cada um dos ambientes compreende eventos que se sucedem linearmente, sem pausas, em seus respectivos atos. Os diálogos caracterizam-se como intersubjetivos e desfiam-se no presente das ações. Vale frisar que tais intercâmbios não se realizam apenas entre as personagens e, em alguma medida, há o estabelecimento de comunicações entre as épocas divergentes. Por exemplo, em 1932, enquanto relatam a ida de Helena à Igreja, a figura está rezando no episódio de 1929. De maneira semelhante, à direita, perguntam se Marcelo já está desperto e, à esquerda, Joaquim acorda o rapaz. Assim, a composição andradina estabelece superposições intemporais que ressaltam características supostamente imodificáveis de parte do grupo enfocado, como o hábito de rezar e a indisposição ao serviço.

No entanto, nos deslocamentos de um ato a um seguinte, existem indicações sobre os avanços do relógio, como na didascália inicial do ato dois: "a ação do Segundo Plano se passa algum tempo depois e a do Primeiro Plano na mesma semana" (ANDRADE, 1986, p. 146); e no princípio do terceiro: "no Segundo Plano, algum tempo depois; no Primeiro Plano, imediatamente à do segundo ato" (ANDRADE, 1986, p. 171). Rubricas como essas promovem a aceleração do drama e, sobretudo, engendram o dispositivo da interrupção. Descuidadamente, seria possível considerar a retrospecção como o outro preceito desdramatizante de A Moratória. Afinal, o desfecho da trama já se apresenta desde os contextos iniciais - a queda econômica da família ruralista. Inclusive, não há dúvidas de que as personagens gostariam de reviver o passado luxuoso e de abandonar as dificuldades do presente imediato. A despeito dessas informações, a fábula parece identificar-se mais com o procedimento de repetição-variação, o qual permite entrever correspondências válidas entre o presente e o 
pretérito da descendência falida. Nessa lógica, independentemente do período, Marcelo dorme por longas horas, Joaquim reclama da preguiça do filho quanto ao trabalho, e Helena defende as inabilidades do jovem. Preservar certas aparências de riqueza, como se tudo permanecesse inalterado, torna-se preocupação central do pai de Lucília. Sobre a política e a imprensa, as censuras, de certo modo, parecem valer também para anos mais recentes: "com este governo, quem é que pode ter prazer em ler jornais! Só publicam o que eles querem" (ANDRADE, 1986, p. 132). Em contrapartida, a modificação mais significativa é enunciada por Marcelo: "vivemos num mundo diferente, onde o nome não conta mais... E nós só temos o nome" (ANDRADE, 1986, p. 159). Consciente dessa nova situação, Lucília costura vestidos com intuito de garantir o sustento dos quatro.

A aproximação dos espaços de 1929 e 1932, visualizados paralelamente, dá a conhecer tanto o enfraquecimento de uma classe social, quanto as últimas expectativas de restabelecer a época de fortuna e de abundância. Nos primeiros quadros, Joaquim demonstra ser o único a acreditar na reintegração da fazenda e no pagamento das dívidas, especialmente porque, nas palavras dele, "esperança nunca é demais" (ANDRADE, 1986, p. 124). Contudo, na recepção de leitores e espectadores, essas crenças positivas assinalam-se como ilusões um pouco excessivas. $\mathrm{O}$ conhecimento do público sobre os acontecimentos de ambos os anos não permite qualquer engano, a derrocada da família de Lucília é irreversível. Em vista disso, aliados ao procedimento de repetição-variação, percebem-se em A Moratória os efeitos da antecipação. Somente o pai de Marcelo ignora o futuro de obstáculos financeiros e, mesmo após saber da perda definitiva das terras, ainda se preocupa com as jabuticabeiras, o café e o feijão. A montagem espaço-temporal, em comparação com o drama absoluto, quebra associações de causa e efeito, bem como parece organizar-se de modo aleatório. Por essas razões, as sequências de eventos 
apresentam-se como uma possibilidade de jogo do sonho. O enredo de Jorge Andrade, segundo Décio de Almeida Prado, em Apresentação do teatro moderno, desfia "o julgamento de uma sociedade já destruída, ou em vias de aniquilamento" (PRADO, 2001, p. 98). A estância produtora de café ilustra, na ficção, o esmorecimento da hegemonia rural e, na contramarcha, o fortalecimento das grandes cidades brasileiras, como São Paulo.

$\mathrm{O}$ esticar da temporalidade manifesta-se também em Auto da Compadecida, embora de forma diferente das obras já examinadas. As páginas iniciais da fábula literária trazem informações sobre parte dos episódios a serem desenrolados. Primeiro, a criação de Ariano Suassuna baseia-se em três aventuras do imaginário popular nordestino, escritas por autores anônimos: O Castigo da Soberba, O Enterro do Cachorro e História do cavalo que defecava dinheiro. Posteriormente, começando o drama, um Palhaço resume mais dois acontecimentos: "o julgamento de alguns canalhas, entre os quais um sacristão, um padre e um bispo, para exercício da moralidade" (SUASSUNA, 2004, p. 15), e "a intervenção de Nossa Senhora no momento propício, para triunfo da misericórdia" (SUASSUNA, 2004, p. 15). Tais notícias, oferecidas precocemente, sugerem o dispositivo da antecipação. Esse processo de adiantar os quadros dramáticos, em algum nível, minimiza a ansiedade de leitores e espectadores - relacionada com o desconhecimento sobre os fatos. Nesse sistema, produz-se um ritmo inverso, desdramatizante, de retorno ao familiar. Os eventos já relatados têm como protagonistas João Grilo e Chicó, homens de inteligência aparentemente ingênua que se divertem criando uma série de mal-entendidos. As conversações estabelecidas entre eles, e entre as demais figuras, mostram-se intersubjetivas e no presente da ação. Apenas os enunciados transmitidos pelo Palhaço são construídos com outras particularidades, uma vez que ele não aparece em cena como uma simples personagem. Além de prever os feitos mencionados, ele 
organiza as mudanças de cenário, indica as disposições dos atores no espaço e dialoga, sem intermediários, com o público.

No transcorrer do drama, Chicó e João Grilo convencem integrantes da Igreja Católica a conduzir, na língua latina, o enterro de um cachorro. Depois, esperando obter vantagens, ambicionam vender um gato descomedor de moedas. Os objetivos saem do controle quando entra na cidade uma dupla de cangaceiros com sede de dinheiro e assassinato. Boa parte das personagens perde a vida e, ao se converterem em desencarnadas, são transportadas para outra dimensão. Entre as fronteiras do céu e do inferno, deparam-se com a Compadecida (Nossa Senhora), o Manuel (Nosso Senhor Jesus Cristo), o Demônio e o Encourado (Diabo). Essas entidades superiores, divinas e satânicas, deliberam sobre o futuro do grupo: o paraíso ou as trevas? João Grilo repele o caminho do abismo; clama pela interseção de Nossa Senhora da Compadecida, pedindo que seus companheiros ocupem as cinco últimas vagas do purgatório; e promove a oração terminante, com advertência significativa: "lembrem-se de dizer, em vez de 'agora e na hora de nossa morte', 'agora na hora de nossa morte', porque do jeito que nós estamos, está tudo misturado" (SUASSUNA, 2004, p. 160). Após negociações, o rapaz livra os colegas de padecerem no mal e é agraciado com nova oportunidade de viver. Acordando no plano terrestre, reencontra Chicó e as preocupações mundanas, como as necessidades da fome e do sustento. Os eventos dilatados no universo da eternidade, em certa medida, originam o operador da interrupção.

O deslocamento da existência passageira para a infindável suspende limites temporais seguros e resistentes. Continuidades fora da vida não se interessam por obrigações relativas ao cotidiano e, assim, as vinte e quatro horas do dia não fazem qualquer sentido. Os ponteiros do relógio cessam de trabalhar e, principalmente, como bem define Chicó, importa o encontro "com o único mal irremediável, aquilo que é a marca de nosso estranho destino sobre a terra, aquele fato sem explicação que 
iguala tudo que é vivo num só rebanho de condenados, porque tudo que é vivo morre" (SUASSUNA, 2004, p. 123). Todavia, João Grilo prova que o difícil não é necessariamente sem jeito e consegue reverter até mesmo o impossível: regressar à vida. Essas conexões de tempos definidos e indefinidos, marcados e não marcados, acentuam a edificação do jogo dos sonhos. A trama de Auto da Compadecida, com suas várias narrativas fantasiosas, abre caminhos para excluir a necessidade de relações óbvias de causa e efeito. Aceitar a entrada do protagonista no reino dos céus é tão admissível quanto um cavalo bento, um testamento de cachorro, um pirarucu pescador de gente. Talvez a morte de João Grilo tenha sido apenas uma imaginação momentânea, após o susto de um tiro de raspão, como ele mesmo deixa implícito: "fiquei com a vista escura e, quando acordei, estava na rede e vocês iam me enterrar" (SUASSUNA, 2004, p. 181). Sem resolver por uma das alternativas, realça-se na obra de Ariano Suassuna a abdicação "de um realismo verista em troca de uma outra realidade, feita de sobrenatural e de poesia" (MAGALDI, 2004, p. 241), como sintetiza Sábato Magaldi, em Panorama do teatro brasileiro.

Questões pertinentes à forma dramática atravessam os séculos e não param de suscitar novidades ou incertezas. Dramaturgos e teóricos parecem variar entre seleções ora inclinadas a aparências mais fechadas, unificadas em apenas um conflito, ora propensas a configurações mais abertas, fragmentadas em cenas descontínuas. Essas separações, quando muito isoladas e opostas, necessitam de abstrações didáticas. A Poética de Aristóteles, muitas vezes categorizada como um aglomerado de normas, talvez prefira encenações de tragédias compreendidas em uma passagem de sol e fábulas encadeadas por início, meio e fim, em ordem fixa. O conceito de drama absoluto, de Peter Szondi (2001), enfatiza os vínculos intersubjetivos das comunicações entre, pelo menos, duas personagens e os acontecimentos desenvolvidos no presente da ação. A imagem de drama-da-vida, de Jean-Pierre Sarrazac (2017), realça 
a flexibilização dos contornos dramatúrgicos a partir da assimilação de procedimentos epicizantes, como a frequência de relatos pretéritos e da dimensão intrassubjetiva das personagens. Neste corrente texto, importa acompanhar ao menos parte das dilatações da temporalidade incorporadas à forma dramática, ao longo dos séculos.

A seleção das obras dramatúrgicas procura enredos, do teatro brasileiro moderno, que estabeleçam intercâmbios com as teorizações estrangeiras. Não se pretende aqui simplesmente reduzir as particularidades das composições teatrais a meras definições preestabelecidas. Ao contrário, tenciona-se buscar pontos em comum entre essas instâncias e promover discussões, sem necessariamente propor conclusões estáveis ou rígidas. Vestido de Noiva, de Nelson Rodrigues, oscila entre as comunicações intersubjetivas e intrassubjetivas, entre as ocorrências do passado e do presente. Os planos da realidade, da memória e da alucinação percorrem as linhas desdramatizantes da retrospecção, da interrupção e da optação, desencadeando uma espécie de fim de jogo ou de jogo dos sonhos. A Moratória, de Jorge Andrade, alterna-se entre os anos de 1929 e 1932, apresentando, lado a lado, a decadência financeira de uma família. Os diálogos são intersubjetivos, no presente da ação, mas há um constante jogo de sonhos repleto de avanços e recuos do relógio, com interrupções, repetições-variações, antecipações. Auto da Compadecida, de Ariano Suassuna, fundamenta-se em três breves histórias do populário nordestino e, assim, promove a antecipação de fatos. A composição divide-se entre a vida e a morte das personagens, com falas intersubjetivas, no presente da ação, em um jogo de sonhos imerso em interrupções. Nesses moldes, inferem-se dilatações temporais para além da solidez do início, meio e fim, bem como construções de fábulas capazes de abrigar, em textos únicos, a vida inteira de Alaíde; de Joaquim, Helena, Marcelo e Lucília; de João Grilo e Chicó, ainda que apenas metonimicamente. 


\section{Referências}

ANDRADE, Jorge. A Moratória. In: ANDRADE, Jorge. Marta, a árvore e o relógio. São Paulo: Perspectiva, 1986. p. 117-187.

ARISTÓTELES. Poética. 8. ed. Tradução de Eudoro de Souza. Lisboa: Imprensa Nacional-Casa da Moeda, 2008.

GUZIK, Alberto. A Dramaturgia Moderna. In: FARIA, João Roberto (dir.). História do teatro brasileiro: do modernismo às tendências contemporâneas. São Paulo: Perspectiva: Edições SESCSP, 2013. v. 2. p. $117-143$.

MAGALDI, Sábato. Panorama do teatro brasileiro. São Paulo: Global, 2004.

MEDEIROS, Elen de. Um teatro bagunça: o drama moderno brasileiro em perspectiva. Curitiba: Editora Prismas, 2017.

PRADO, Décio Almeida de. Apresentação do teatro brasileiro moderno. São Paulo: Perspectiva, 2001.

RODRIGUES, Nelson. Vestido de noiva. 2. ed. Rio de Janeiro: Nova Fronteira, 2004.

ROUBINE, Jean-Jacques. Introdução às grandes teorias do teatro. Tradução de André Telles. Rio de Janeiro: Zahar, 2003.

SARRAZAC, Jean-Pierre. Poética do drama moderno: de Ibsen a Koltès. Tradução de Newton Cunha, J. Guinsburg, Sônia Azevedo. São Paulo: Perspectiva, 2017.

SOUZA, Roberto Acízelo de. Teoria da Literatura. 5. ed. São Paulo: Ática, 1995.

SUASSUNA, Ariano. Auto da Compadecida. Rio de Janeiro: Agir, 2004. 
SZONDI, Peter. Teoria do drama moderno [1880-1950]. Tradução de Luiz Sérgio Rêpa. São Paulo: Cosac \& Naify Edições, 2001.

Artigo recebido em: 15/08/2019

Aprovado em: 19/05/2020 